\title{
Intraabdominal hypertension and abdominal compartment syndrome in the intensive care unit
}

\author{
DANIELA BANDIĆ PAVLOVIĆ $(\triangle) \bullet$ \\ VIŠNJA MAJERIĆ KOGLER \\ Department of Anesthesiology \\ and Intensive Care Unit \\ University Hospital Center Zagreb, \\ Zagreb, Croatia \\ e-mail: debandic@inet.hr
}

\section{DANIELA BANDIĆ PAVLOVIĆ • VIŠNJA MAJERIĆ KOGLER}

\begin{abstract}
Intraabdominal hypertension can induce a significant dysfunction of cardiovascular, respiratory, renal, and gastrointestinal and central nervous systems. Recently, a prospective multicenter epidemiological study concluded that the intraabdominal hypertension observed in intensive care units was associated with an increased risk of mortality in critically ill patients. In this review, we summarize current literature data concerning definitions and measurement of intraabdominal pressure and discuss the importance of intraabdominal hypertension in critically ill patients. We conclude that intraabdominal pressure should be taken into consideration along with other standard pressure measurements in critically ill patients.
\end{abstract}

Key words: intraabdominal pressure, intraabdominal hypertension, abdominal compartment syndrome Introduction

Compliance of the abdominal wall together with the abdominal content determines the intraabdominal pressure (IAP). Normally, the values of IAP in patients breathing spontaneously is atmospheric, or just sub atmospheric (1). Although terms intraabdominal hypertension and abdominal com-partment syndrome (ACS) are known for more than a century, there has been confusion in their distinction. Generally speaking, intraabdominal hypertension $(\mathrm{IAH})$ is a value of IAP causing a pathophysiological effect on organ systems, and ACS is a consequence of $\mathrm{IAH}$ effect over some time. Initially, both terms were associated only with trauma patients or surgical patients, but later these terms were also used in relation to other medical patients. The fact that IAH is present in 18 to $80 \%$ of ICU patients explain the increased interest in this topic (2).

\section{Intraabdominal hyperten- sion and measurement of the IAP}

IAP is measured directly by an intraperitoneal catheter or indirectly by a percutaneous inferior vena cava catheter, nasogastric catheter or urinary bladder catheter. Intravesicular pressure (IVP) measurement is now accepted as the gold standard because this method is simple, considerably accurate and widely available. In 1984 Kron et al. first described the method of IVP measurement in ACS after ruptured abdominal aortic aneurysm (3). IAP should be measured at end-expiration, in the supine position, after the bladder is firstly fully emptied, and then filled with $50 \mathrm{ml}$ of saline. The degree of muscle relaxation as well as body weight has an affect on the measurement. Continuous IAP measurement using a nasogastric tube as well as continuous bladder irigation methods are now automated and they represent the most accurate methods in clinical practice.
Different authors use different cut-off points for defining IAH $(4,5,6,7)$. Sugrue et al. reported that even IAP of 10 $\mathrm{mmHg}\left(1 \mathrm{mmHg}=1.36 \mathrm{~cm} \mathrm{H}_{2} \mathrm{O}\right)$ might induce harm to several organ systems (6). Recently, at the World Congress on Abdominal Compartment Syndrome, the threshold for IAH was established as a value of $12 \mathrm{mmHg}$ or greater in a minimum of three standardized measurements taken four to six hours apart (8). Four severity groups have been established on to basis of intraabdominal pressure values: grade 1, 12-15 $\mathrm{mmHg}$; grade 2 , 16-20 mmHg; grade 3, 21-25 mmHg; grade 4, greater than $25 \mathrm{mmHg}$ (8).

\section{Intraabdominal hyperten- sion induces organ system failure}

Current data concerning the $\mathrm{IAH}$ and ACS is rather large, but definitions are not clear. Malbrain et al. defined ACS as IAH greater than $20 \mathrm{mmHg}$ in combination with at least one end-organ failure (2). Mc Nellis et al. defined ACS in surgical ICUs as IAP greater than 25 
$\mathrm{mmHg}$ in combination with oliguria and peak airway pressure greater than 50 $\mathrm{mmHg}$ (9). The latest definition of ACS includes two main characteristics: an IAP of $20 \mathrm{mmHg}$ or greater in a minimum of three standardized measurements taken four to six hour apart and at least one new end-organ failure (8). Besides, the abdominal perfusion pressure, defined as the difference between arterial pressure and IAP, less than 50 $\mathrm{mmHg}$ is an additional factor but not mandatory (8). According to experimental and clinical reports, the presence of IAH affecting several abdominal and extra abdominal organs leads to multiple organ failure and eventually to death. It is observed that gastrointestinal and renal systems are usually affected first.

Elevated IAP induces splanchnic hypo perfusion hence decreased intestinal perfusion. Polat et al. reported bacterial translocation at the IAP>14 mmHg (10) while another group of authors described bacterial translocation at the IAP of $20 \mathrm{mmHg}$ (11). It is assumed that intestinal ischemia might cause multiple organ dysfunction syndrome mediated by the inflammatory response. Secondary acute respiratory distress syndrome (ARDS) has been observed in several studies $(12,13,14,15)$. Oda et al. evaluated the activation of pro inflammatory cytokines in Yorkshire swine after causing hemorrhagic shock and resuscitation (HS-R) and after ACS (14). They observed greater cytokine activation and lung injury than in HS-R alone.

Acute renal failure develops as a secondary complication in IAH. Decreased renal plasma flow, lower glomerular filtration and smaller urine output with normal urinary sodium are the main characteristics. One of the first visible signs of IAH is oliguria which occurr at an IAP of 15-20 mmHg. Diuresis and renal function recovery are observed following abdominal decompression. Mechanisms of renal dysfunction are unclear, although increased renal vein pressure could be the main cause (16)
On the other hand, ureteric re- canalization with ureteric stents following the obstruction does not improve renal function.

$\mathrm{IAH}$ also leads to respiratory dysfunction having a direct mechanical effect by displacing the diaphragm cranially. ACS affecting pulmonary function leads to increased peak airway pressure, compressive atelectasis, decreased lung compliance and reduced lung volumes. Besides, ventilation-perfusion mismatch with increased dead space occurs and leads to intrapulmonary shunts. The overall effect is an impairment of gas exchange, with hypoxemia, hypercapnia and acidosis (15, 16, and 17).

Neurological effects of raised IAP are characterized by intracranial hypertension and decreased cerebral perfusion pressure (18). The mechanism is unknown. Neurological problems, in patients with ACS but without any head trauma are observed, and therefore require close monitoring of both IAP and neurological status (18).

Ventricular filling is also affected in patients with $\mathrm{IAH}$ as a resultat of decreased venous return caused by the compression of the inferior vena cava or portal vein. While the intravascular volume is decreased, preload measurements, central venous pressure (CVP) and pulmonary artery occlusion pressure (PAOP), are falsely elevated (19). Some author noted that right ventricular end-diastolic volume (RVEDV) and global end-diastolic volume index (GEDVI) reflect intravascular volume status more accurately $(16,19,20)$. Therefore, these volumetric parameters should be used for preload estimation and fluid resuscitation in patients with ACS.

\section{Risk factors}

Identification of patients with IAH is critical. It is important to remember that ACS can develop in all critically ill patients. ACS mostly occurs following trauma and damage control surgery associated with the compressive effect of intraabdominal packing, coagulopathy dis- orders, bowel edema and fascial or skin closure (15). Several trials compared patients who developed ACS with control groups. Using a multivariate analysis model, high PAP and volume of fluid resuscitation were identified as risk factors for ACS $(21,22)$.

A recently conducted, multicenter, epidemio-logical study in patients with $\mathrm{IAH}$ was published in 2005. This trial prospectively enrolled 265 mixed ICU patients (medical and surgical) in 14 ICU in six countries. Thirty two percent of patients had IAH with IAP greater than $12 \mathrm{mmHg}$ and $4.2 \%$ had ACS (IAP greater than $20 \mathrm{mmHg}$, with at least one organ failure) on admission. During the stay in ICU, IAH was an independent risk factor for mortality, whereas $\mathrm{IAH}$ on admission was not a predictor of mortality. They observed that abdominal surgery, fluid resuscitation, ileus and liver dysfunction were independent predictors for IAH (2)

\section{Prevention and treatment}

In addition to the standard patient monitoring of urine output and cardio respiratory function, an intermittent IVP is mandatory in most critically ill patients. Raised IVP necessitate continuous IAP measurement to ensure optimal patient management. The first step in the management of the ACS is fluid recovery and general support to optimize the condition of the patient. state. On the other hand, fluid overload is a risk factor leading to deterioration of ACS. RVEDV and GVEDV are the main indicators of the fluid state.

According to Meldrum and Burch, an IAP of $25 \mathrm{mmHg}$, is a pressure value at which anuria, decreased cardiac output and increased PAP often complicate IAH $(7,23)$.. Surgical decompression should be the treatment of choice in ACS (24). Some authors advocate surgical decompression as a preventive method, but due to its morbidity, it is not widely accepted (8). Several different methods of surgical release are in use but temporary abdominal closure is today the most accepted method 
(8). Critical IAP for surgical decompression is not yet defined, but practitioners should note all pathophysiologic effects related to ACS and act accordingly. Reversal of organ deterioration in addition to normalization of preload, pulmonary function, splanchnic circulation and diuresis in ACS is observed after abdominal decompression $(7,16,25)$.

\section{Conclusion}

Finally, we have to point out that IAP is a common problem in the ICU patients; therefore practitioners in critical care units should be aware of this issue. Marked or sustained IAH compromises almost every organ system, and also potentates the development of MOF.
Close monitoring of IAP in patients at risk along with other pressure measurement is mandatory. Identification of patients and treatment before irreversible organ derangements occur is crucial. The cornerstones of treatment are general support with fluid optimization and surgical decompression of the abdomen.

\section{REFERENCES}

1. Moffa SM, Quinn JV, Slotman GJ. Haemodynamic effects of carbon dioxide pneumoperitoneum during mechanical ventilation and positive end-expiratory pressure. J Trauma 1993;35:613-7.

2. Malbrain ML, Chiumello D, Pelosi P, Bihari D, Innes R, Ranieri M, Del Turco M, Wilmer A, Brienza N, Malcangi V, Cohen J, Japiassu A, De Keulenaer BL, Daelemans R, Jacquet L, Laterre PF, Frank G, Souza P, Cesana B, Gattinoni L. Incidence and prognosis of intraabdominal hypertension in a mixed population of critically ill patients: A multiple-center epidemiological study. Crit Care Med 2005;33:315-22.

3. Kron IL, Harman PK, Nolan AP. The measurement of intra-abdominal pressure as a criterion for abdominal re-exploration. Ann Surg 1984;199:28-30

4. Wiedergren JT, Battistella FD. The open abdomen treatment for intraabdominal compartment syndrome. J Trauma 1994;37:158.

5. Ivatury RR, Sugerman HJ. Abdominal compartment syndrome: a century later, isn't it time to pay attention? Crit Care Med 2000;28:2137-8.

6. Sugrue M, Jones F, Lee A, Buist MD, Deane S, Bauman A, Hillman K. Intra-abdominal pressure and gastric intramucosal pH: is there an association? World J Surg 1996;20:988-91.

7. Burch JM, Moore EE, Moore FA, Franciose R. The abdominal compartment syndrome. Surg Clin North Am 1996;76:833-42.

8. Sugrue M. Abdominal compartment syndrome. Curr Opinion in Critical Care 2005;11:333-8.

9. McNelis J, Marini CP, Simms HH. Abdominal compartment syndrome: clinical manifestations and predictive factors. Curr Opin Critical Care 2003;9:133-6.

10. Polat c, Aktepe OC, Akbulut G, et al. The effects of increased intraabdominal pressure on bacterial translocation. Yonsei Med J 2003;44:259-64.

11. Diebel LN, Dulchavsky SA, Brown WJ. Splanchnic ischemia and bacterial translocation in the abdominal compartment syndrome. J Trauma 1997;43:852-5.

12. Rouby JJ, Puybasset L, Nieszkowska A, Lu Q. Acute respiratory distress syndrome: lessons from computed tomography of the whole lung. Crit Care Med 2003;31 (suppl):S285-S295.

13. Pelosi P, D'Onofrio D, Chiumello D, Paolo S, Chiara G, Capelozzi VL, Barbas CS, Chiaranda M, Gattinoni L. Pulmonary and extrapulmonary acute respiratory distress syndrome are different. Eur Respir J Suppl 2003;42:48s-56s.

14. Oda J, Ivatury RR, Blocher CR, Malhotra AJ, Sugerman HJ. Amplified cytokine response and lung injury by sequential hemorrhagic shock and abdominal compartment syndrome in a laboratory model of ischemia-reperfusion. J Trauma 2002;52(4):625-32.

15. Morken J, West MA. Abdominal compartment syndrome in the intensive care unit. Curr Opin Crit Care 2001;7:268-74.

16. Cullen DJ, Coyle JP, Teplick R, Long MC. Cardiovascular, pulmonary and renal effects of massively increased intra-abdominal pressure in critically ill patients. Crit Care Med 1989;17:118-21

17. Richardson JD, Trinkle JK. Haemodynamic and respiratory alterations with increased intra-abdominal pressure. J Surg Res 1976;20:401-4.

18. Deeren D, Dits H, Malbrain ML. Corellation between intra-abdominal and intracranial pressure in nontraumatic brain injury. Intensive Care Med 2005;31:1577-81.

19. Schachtrupp A, Graf J, Tons C, Hoer J, Fackeldey V, Schumpelick V. Intravascular volume depletion in a 24-hour porcine model of intraabdominal hypertension. J Trauma 2003;55:734-40.

20. Cheatham ML, Nelson LD, Chang MC, Safcsak K. Right ventricular end-diastolic volume index as a predictor of preload status in patients on positive end-expiratory pressure. Crit Care Med 1998;26:1801-6.

21. Ivatury RR, Porter JM, Simon RJ, Islam S, John R, StahI WM. Intra-abdominal hypertension after life-threatening penetrating abdominal trauma: prophylaxis, incidence, and clinicawl relevance to gastric mucosal pH and abdominal compartment syndrome. J Trauma 1998;44:1016-23.

22. McNelis J, Marini CP, Jurkiewicz A, Fields S, Caplin D, Stein D, Ritter G, Nathan I, Simms HH. Predictive factors associated with the development of abdominal compartment syndrome in the surgical intensive care unit. Arch Surg 2002;137:133-6.

23. Meldrum DR, Moore FA, Moore EE, Franciose RJ, Sauaia A, Burch JM. Prospective characterization and selective management of the abdominal compartment syndrome. Am J Surg 1997;174:667-72; discussion 672-3.

24. Schachtrupp A, Fackeldey V, Klinge U, Hoer J, Tittel A, Toens C, Schumpelick V. Temporary closure of the abdominal wall (laparostomy). Hernia 2002;6:155-62.

25. Chang MC, Miller PR, D'Agostino R Jr, Meredith JW. Effects of abdominal decompression on cardiopulmonary function and visceral perfusion in patients with intra-abdominal hypertension. J Trauma 1998;44(3):440-5. 